\title{
Takotsubo after general anesthesia for chronic subdural hematoma: case report
}

\author{
Lea Skorup ${ }^{1 *}$, David Gobić ${ }^{2}$, Vjekoslav Tomulić ${ }^{2}$ Davorka Lulić', Teodora Zaninović Jurjević2, Luka \\ Zaputović, Alen Ružić ${ }^{2}$ \\ ${ }^{1}$ Department of Emergency Medicine of County of Primorje-Gorski kotar, Rijeka, Croatia \\ ${ }^{2}$ University of Rijeka School of Medicine, University Hospital Centre Rijeka, Rijeka, Croatia
}

The goal: Takotsubo cardiomyopathy is an acute cardiovascular disease generally characterized by reversible wall motion abnormalities of the left ventricle, electrocardiographic changes and clinical presentation that can mimic myocardial infarction in the absence of an obstructive coronary artery disease. It is often precipitated by an intense acute emotional or physical stress. Our goal was to present a patient with Takotsubo cardiomyopathy which developed after the induction of general anesthesia.

Patient and Methods: The patient's available medical record was used to present the clinical course of Takotsubo that developed after induction of general anesthesia.

Results: We present a case of a 61-year-old woman who developed Takotsubo cardiomyopathy during operation of chronic subdural hematoma. After induction of general en-

\footnotetext{
Received: $20^{\text {th }}$ Apr 2014

${ }^{*}$ Address for correspondence: Zavod za hitnu medicinu Primorsko-goranske županije, B. Blečića bb, HR-51000 Rijeka, Croatia.

Phone: $+385-91-7328081$

E-mail: skoruplea@gmail.com
}

dotracheal anesthesia and preparation of the operative field, hemodinamic instability was detected. The ECG lead to suspect on acute myocardial infarction. Coronarography with the left ventriculography was performed indicating development of takotsubo cardiomyopathy. The patient was admitted to the cardiac intensive care unit and treated according to the ongoing hemodynamic disturbances. By the day eight, clinical recovery was observed with anterior wall hypokinesis. The patient was hemodynamically stabile with normal blood pressure and pulse.

Conclusion: There are already many case reports presenting numerous possible triggering factors for Takotsubo cardiomyopathy. Severe stress, emotional or physical, can precede this disease. This is an interesting case where iatrogenic stress related to medical procedures causes transient systolic dysfunction of the heart, mimicking myocardial infarction.

KEYWORDS: acute myocardial infarction, Takotsubo cardiomyopathy, general anesthesia.

CITATION: Cardiol Croat. 2014;9(5-6):173.

\section{Literature}

1. Castillo Rivera AM, Ruiz-Bailén M, Rucabado Aguilar L. Takotsubo cardiomyopathy - a clinical review. Med Sci Monit, 2011;17(6):135-47.

2. Kurowski V, Kaiser A, von Hof K, et al.Apical and midventricular transient left ventricular dysfunction syndrome (tako-tsubo cardiomyopathy): frequency, mechanisms, and prognosis. Chest. 2007;132(3):809-16.

3. Littlejohn CF, Syed O, Ornstein E, Connolly ES, Heyer EJ. Takotsubo cardiomyopathy associated with anesthesia: three case reports. Cases J. 2008;1(1):227. 